\title{
AN APPROACH TO PACKAGING WASTE REVERSE LOGISTICS: CASE OF SLOVENIA
}

\author{
Andrej LISEC ${ }^{\star}$, Slobodan ANTIĆ ${ }^{2}$, Francisco CAMPUZANO-BOLARÍN ${ }^{3}$, Vaska PEJIĆ ${ }^{4}$ \\ ${ }^{1,4}$ Faculty of Logistics, University of Maribor, Slovenia \\ ${ }^{2}$ Faculty of Organisational Sciences, Univeristy of Belgrade, Serbia \\ ${ }^{3}$ Dept of Business Economics, Polytechnic University of Cartagen, Spain
}

Received 2 June 2015; revised 8 March 2016, 8 April 2016, 1 July 2016; accepted 10 July 2016;

first published online 25 May 2017

\begin{abstract}
Deriving from insights gained in a concrete empirical quantitative modelling research, the aim of the paper is to present the methodology and results of a Packaging Waste (PW) logistics exploratory study that was conducted in cooperation with a leading southeastern European retail chain company. PW Reverse Logistics (RL) is specific, but an integral part of retail operations and can also represent significant logistics and transportation costs concerns. In our research, we have, with a simulation model, been able to reduce the number of tonne-kilometres for $55 \%$ which represents significant cost reduction. The study scope focuses on the RL of industrial PW as the handling object of interest in retail, decoupled from the possible returns flow of non-food items and waste generated on premise by shoppers and employees, classified as non-industrial. It introduces an analytical framework, which has been tested and applied to a real case problem.
\end{abstract}

Keywords: logistics, reverse logistics, retailing, packaging waste, handling.

\section{Notations}

DEA - Data Envelopment Analysis;

DC - Distribution Centre;

FMCG - Fast-Moving Consumer Goods;

HM - hypermarket;

MCDM - Multi-Criteria Decision-Making;

MRF - Material Recovery Facility

PCKG - packaging;

PW - Packaging Waste;

PWM - Packaging Waste Management;

PWMC - Packaging Waste Management Company;

PWMS - Packaging Waste Management System;

RC - Retail Centre;

RL - Reverse Logistics;

RLC - Roll Container;

ROP - Retail unit or Origination Point;

RS - Retail Shop;

SM - supermarket;

WM - Waste Management;

WMS - Waste Management System.

\section{Introduction}

Principles of sustainable development have been steadily permeating into business reality from the realm of declaration constructs and political rhetoric through purposively oriented legislation and corporate citizenship initiatives. Minimizing the ratio between the materials needed to maintain a certain level of economic activity and the provision of goods and services, waste prevention and reduction of the share of its disposal and exploiting residuals as secondary resources instead of virgin raw materials are an economy-wide commonplace.

A significant retail logistics and supply chain transformation is expected (Fernie et al. 2010) where retail companies have become the architects of supply chain from supply to consumption. In such environment, retailers play a double role: that of consumption enablers or catalysts and generators of significant (negative) direct footprint themselves, by their own operations. Logistics in retail may be perceived as equal to production in manufacturing and packaging being its integral component is inherently present in associated material flows that are furthermore closely correlated with the level of commercial activity (Triantafyllou, Cherrett

*Corresponding author. E-mail: andrej.lisec@um.si 
2010). Consequently, every item issued, shipped, distributed, received, stored and sold leaves a trail of residuals and packaging is ultimately according to McLeod et al. (2008): '... the most significant waste stream produced by the retail sector.'

The overall goal of the research study with a detailed case illustration/analysis, which was set by the company, was to gain a better understanding of the existing PWMS on domestic Slovenian market and improve the visibility of its underlying processes, specifically on the store level. An additional request was to conceptualize a model for PWM cost allocation in reference to the waste origination points - sources represented by individual retail units. Those make up a network of 516 retail locations (excluding franchises and company-operated restaurants and tourist agency offices), which are supplied from 9 distribution locations, with a yearly cumulative output of sorted and collected PW refuse from all domestic locations company-wide exceeding 11000 tonnes. Novelty and contribution of the paper are the optimizations of the PW transportation system which represents a significant $(55 \%)$ reduction in a number of tonne-kilometres.

The structure of the paper is organized as follows. After the introduction, Section 1 contains literature review. The methodology and problem description are explained in Section 2, also, Section 3 provides our empirical part, Section 4 presents analysis, and final results, Section 5 expains policy implications for decisions makers. Conclusions are presented in the last section.

\section{Literature review}

Waste is defined by Waste Framework directive (EEC 1975) as 'any substance or object which the holder disposes of or is required to dispose of'. The urban waste market has evolved significantly in the past decades, which among other changes, has led to the creation of new utilities and new business models (Guimarães et al. 2010). PW has been characterized as being an important and growing waste stream (EEA 2005). McKinnon (Fernie et.al. 2010) identified 6 components of retail logistics transformation, one of them being the augmented involvement of retailers in RL operations, amplified by increased flow of PCKG and handling equipment returned for later treatment or re-use. Efficiency in connection to retail RL was studied in DfT (2004) on the segment of product returns. PCKG RL with consumerbased primary PCKG return system possibilities was researched in a project, reported by McGhie (2001). Retail WM was already studied in the context of city logistics reverse flows (McLeod et al. 2008; Maynard, Cherrett 2009) or on the scope of a dedicated shopping centre (Triantafyllou, Cherrett 2010). Pitt (2005) focused on the performance of a group of UK shopping centres in regard to waste production and disposal over several years while facility-centred WM efficiency had additionally been extended also to airports (Pitt, Smith 2003). An inverse logistics and recycling facilities network evaluation system was developed and applied to collecting and recycling municipal waste plastics by means of simulation and virtual engineering by Yoshinaga et al. (2002). Further outside retail domain construction site material and waste flow was modelled and examined (Shakantu et al. 2008), while Hogland and Stenis (2000) conducted an assessment and analysis of an industrial WMS at a large paper company and Abeliotis et al. (2009) developed a decision support system for analysing solid WMS on national and municipal level. Methodologically, European Commission Directorate-General Environment (EC DGE 2012) proposes a WM planning guidance and UNEP (2009) sets forth basic analytical perspectives on WMS. Finally, literature review revealed at least 4 distinctive - though not mutually exclusive - concepts of efficiency: physical (Samuelsson, Tilanus 1997), technical DEA (Cooper et al. 2011), economic (applied to environmental policy measures in EEA (2005)) and ecoefficiency (WBCSD 2000), that are potentially applicable to the problem of WMS evaluation. Practical results of the projec $t$ for leading southeastern European retail Chain Company in packaging are presented in Šimenc and Lisec (2012). The industry is not paying for the full costs of PWM in any of the countries (the transfers plus other financial benefits are not enough to cover the costs of local authorities) (Da Cruz et al. 2014).

\section{Methodology and problem description}

Research aim required a development of an analytical framework which conceptually directed data collection and analysis and highlighted different problem-specific areas that were included and examined in the research, to conceptualize a model for PWM cost allocation in reference to the waste origination points - sources represented by individual retail units, possible rationalization of trips and therefore reducing transportation costs.

PCKG WMS (PWMS) efficiency evaluation was carried out for one of Slovenia's leading retailers, commanding a more than $30 \%$ market share and with an annual turnover nearing 3 billion euros. A company is the single biggest corporate waste producer, having generated over $8 \%$ of all commercial waste, generated by commerce, trade and motor vehicle maintenance sector. Several factors, making retail PCKG WM (PWM) in general and in our topical case a pressing issue with specific implications were identified:

- sheer material volume;

- the spread of origination points;

- source-based sorting;

- legislative requirements and constraints regarding PW collection and recovery (EC 2008, 1994; EEA 2005);

- questionable internal closed loop recycling feasibility (apart from returnable transport items and other handling equipment re-use);

- limited potential for seamless inter-firm by-product exchange (resulting from differences within separate supply chains (McLeod et al. 2008));

- FMCG assortment price sensitivity to any costs incurred by extra activities. 
In next several quarters the company intends to implement a set of measures as part of its strategic WM plan:

- updating internal WM policies and guideline;

- centralized electronic waste register launch;

- mapping of WM processes;

- tenant relationship integration within WM practice.

The main criterion for selecting the collection centre is Euclidean distance between the point of origin or $\mathrm{RC}$ and termination points or a chosen collection centre. In Figure 1 we can see the origin marked with a red circle and sinks marked with blue squares. In the decisionmaking process, we are dealing with 15 sources and 8 sinks. Decision parameter $d_{i j}$ represents a radial distance between the $i$ source and $j$ sink.

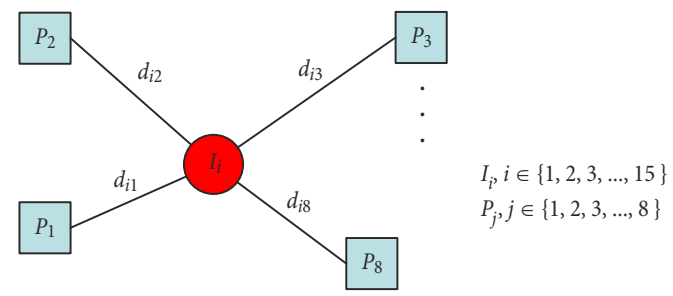

Figure 1. Symbolic display between the sources and sinks

The mathematical model with which we assign a single source location to the nearest collection centre is shown in Equation, where $Z$ represents the objective function that we want to minimize. The objective function is the sum of the distances between collection centres and their closest sources of PW generation. In the model appears a vector of decision variables $X_{i}$, which tells us the source location assigned to each collection centre. Given that our goal represents the allocation of each original site to a single collection centre, only one component of the vector has the value 1 and all other elements 0 . Euclidean distances of the $i$-th original site to all other collection centre recorded in the vector.

$$
\begin{aligned}
& \min Z=\sum_{i=1}^{15} \bar{X}_{i} \cdot D_{i}= \\
& \bar{X}_{1} \cdot D_{1}+\bar{X}_{2} \cdot D_{2}+\ldots+\bar{X}_{15} \cdot D_{15}= \\
& \left(x_{11} \cdot d_{11}+x_{12} \cdot d_{12}+x_{13} \cdot d_{13}+x_{14} \cdot d_{14}+\right. \\
& \left.x_{11} \cdot d_{11}+x_{12} \cdot d_{12}+x_{13} \cdot d_{13}+x_{14} \cdot d_{14}+\right)+\ldots
\end{aligned}
$$

restrictions:

$$
\begin{aligned}
& x_{11}+x_{12}+x_{13}+x_{14}+x_{15}+x_{16}+x_{17}+x_{18}=1 ; \\
& x_{21}+x_{22}+x_{23}+x_{24}+x_{25}+x_{26}+x_{27}+x_{28}=1 ; \\
& \ldots \\
& x_{151}+x_{152}+x_{153}+x_{154}+x_{155}+x_{156}+x_{157}+x_{158}=1 ; \\
& x_{i j} \in\{0,1\}, d_{i j} \geq 0, i \in\{1,2, \ldots, 15\}, j \in\{1,2, \ldots, 8\} .
\end{aligned}
$$

\section{Research work: case study}

Research study work breakdown structure followed the process of WM planning and methodology set out in EC DGE (2012) as a detailed case analysis. We derived from 3 WMS analytical perspectives when defining the domain and setting the basis for the research (UNEP 2009): life-cycle, management and generational. Against that backdrop, existing topically-related research was used to refine the study proposition and methods, although similarly focused and comprehensive (in design and scope) studies are not common. Epitomizing the research aim, the main study question was formulated as follows: What is the efficiency of PWMS and how is PWM implemented and actually performed in the specific setting? The primary unit of analysis was the conceptual entity of PWMS at the respective retailer. Being a less well-defined unit of analysis (Yin 2013), a detailed case analysis would further evolve into a single-case embedded case-study design (Yin 2013). A designated HM assumed the role of the primary embedded unit that would serve as the representational abstraction of the superior research problem (PWMS), offering the examination of PWMS' specific operational details. It was selected firstly because HMs as the largest and most complex retail units include the entire range of $\mathrm{RL}$ activities, exhibited by a retail network and secondly, the concrete store was moderate to strongly correlated with 14 out of 21 HMs on the basis of monthly PW output, the most out of all HMs (Figure 2). The HM was the largest part of a shopping centre, which is owned and managed by the retailer who is also its anchor tenant. Furthermore, additional supportive embedded units were included for comparative and derived validation purposes, research instruments testing and case-related scope integrity. The inter- and inner- format replication was confirmed by visiting 2 other HMs, 2 SMs and 2 RSs through videodocumenting, process-mapping and comparing associated PWM processes. The focus was on the retail backoffice, where pure PWM activities were not just an integral part of regular process, no other functional units such as sales goods were bundled in the activity and excluding certain movements or handling that would have been performed regardless of PW presence (such as shop-floor handling and return when re-stocking). The reverse flow of interest was limited to commercial PW (secondary and tertiary PCKG (EC 1994)). HugeBrodin's (1997) perspective of RL systems was adopted with the addition of collection phase and minus re-processing, considering the reverse feedback loop as a supply chain on its own. PCKG design and minimization were thus intentionally omitted (dealing with the waste generation profile as it is), however, they also were not included in the scope of the underlying project. Multiple sources of evidence were used, consisting of focused interviews with executive logistics director, executive purchasing advisor and environmental department team members, with whom 2 milestone meetings were carried out during the project; waste stream measurements at the selected source by means of weighing; on-site 


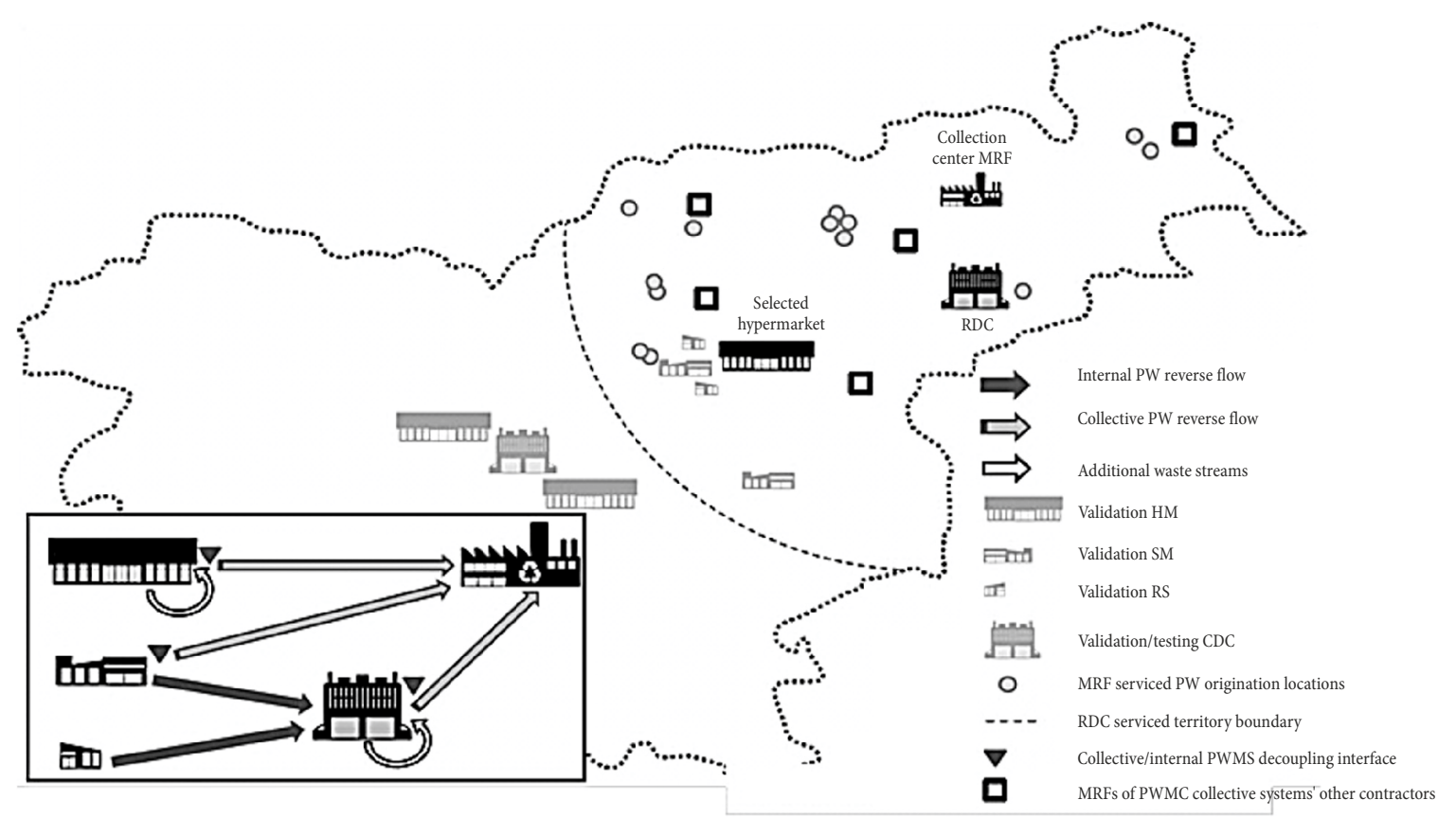

Figure 2. Examined PWM network subsystem and its accompanying RL channel structure

employee open-ended interviews, process analysis and mapping through direct and participant observation; and PWMS policy documentation and archival records, considering the PW collected on company and selected origination points level. Finally, findings were reported and discussed with the companies' internal stakeholders (logistics, environmental, sales and purchasing representatives alongside the respective management board member) and the management of PWMC, who runs the collective PWMS.

\section{Analysis and results}

Company is a part of a collective PWM system and utilizes a partially integrated outbound and RL network configuration and disposition in an open-loop collective system, according to its organization (DfT 2004) and material flow (Bain et al. 2009), respectively. Internal PW reverse flow starts with the process of primary collection at the source (origination point) which is the ROP, where PW is generated: on the shop-floor when the goods are re-stocked at the shelf (then on the return to the storage area PW is sorted and transferred usually from a shopping trolley - into a RLC), in the storage area during goods receipt and storing (again the $\mathrm{PW}$ is deposited into the respective RLC, depending on the PW type and storage section), during stock-picking in the storage area before shelf replenishment (PW can be deposited into the RLC directly at the point of depacking, or transferred en-route to the shop floor, depending on the original goods storage location). RLC is the basic receptacle and PW handling unit, which is in bigger store formats (HMs, larger SMs) placed at a fixed storage-section-specific collection point, where normally
2 RLCs - 1 for paper and cardboard and 1 for foil and plastics - are situated. A number of collection points in bigger retail formats depends on the number of goods sections (for instance: drinks, confectionery, fruit and vegetables, meat and dairy). When collection RLCs are full, the PW is transported manually to the waste service bay on the loading dock, where the refuse is sorted and transferred by hand into appropriate containers, according to the type of PW (usually there are 3, 1 for each type of PW: paper/cardboard, foil/plastics and wood). Containers represent decoupling interfaces where primary collection ends and the secondary collection in the domain of a 3rd party service provider begins. PW is carried over into the collective reverse flow, which is external to the company and is managed by a waste collector under contract with the PWMC, who represents and manages the umbrella collective system. PW from larger store formats is transported to the collector's MRF by hauling full containers or transhipping the refuse at the ROP into a receiving container on a flatbed truck. In comparison to larger ROP, when the internal PW flow originates from RSs and regular SMs it can be broken into 2 segments: an expanded primary collection (extending beyond in-facility collection), which is coupled with preliminary storage stage. PW is not transferred at ROPs into containers by the collector but awaits pick-up, stored in RLCs, and is backloaded onto retailer's goods delivery vehicles in exchange for primary shipments at each store that was serviced in order to be transported on their return trips back to the regional or central DC later on. The collection is integrated deeper into the retailer's operations, where DCs serve as internal PW flow consolidation points. There, delivery vehicles are unloaded, RLCs with PW are temporarily stored on an appointed 
dock, and are later emptied into collection press containers that compact the refuse. PW is then transported in container-unit loads by the collector to his MRF. The primary collection here does not end with PW handling within the ROP, but includes also the transport to the DC and the internal PW reverse flow integrates an extra stage of preliminary storage of waste pending secondary collection (EC 2008). PW is unloaded and prepared for further pick-up and transport for recovery at the MRF.

Data was analysed and findings interpreted using the proposed framework and contrasted to virtuallyengineered reference options, representing an ideal case situation for the current PWMS evaluation purposes (Figure 3). The framework comprised an efficiency model, integrating different PWMS pillars of efficiency with interdependency areas, which defined the main attributes for evaluation and adhered to 4 general PWMS efficiency principles. Its use was aimed at determining waste stream characteristics (generation quantities, dynamics, composition and treatment), waste origination points, handling locations and technology, PWM processes and corresponding RL channels. In following sections, we present the outline of main framework-derived findings.

PWMS was analysed, considering both, the structural and flow component. The first one concentrates on the overall performance in terms of quantities generated, collected and disposed on a nodal-specific or network-wide level. The outcoming network disposition efficiency was examined by comparing the current network configuration with a simulated ideal scenario where resources (trucks, collection equipment, recovery facilities) from different contractors, operating under the PWMC, whose complying participant is also the retailer, could be pooled together. Such joint RL platform would offer collaborative services, taking the advantage of complementary geographical coverage and capacities.
Associated ideal network flow had been modelled and external flow, managed currently by a single exclusive waste collector was simulated to have been rediverted to alternative destination MRFs (Figure 2), that already operate under the same collective PWMS. This would require an intervention outside the retailer's boundaries, but could potentially significantly improve network efficiency as the company is the scheme's largest PW generator, and such strategic shift in the eastern retailer's network subsystem could lower yearly overall network PW transport intensity in tonne-kilometres on average of up to 55\% (in reference to 2010 baseline PW generation profile).

The company which handles PW in Slovenia is collecting PW from the considered company directly (3rd variant) and indirectly (1st variant) - Figure 4.

In a given analysis we have focused on a transport part of PWM and therefore analysed the transport efficiency of PW (Figure 5) in the case of the largest Slovenian retailer's centres in eastern Slovenia, where PW is removed to collection centre in Lenart which is owned by one of Slovenian companies for WM.

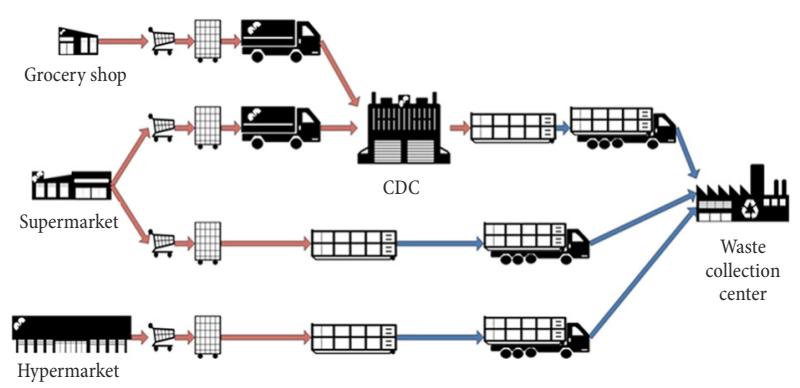

Figure 4. Variants of RL in the respective company

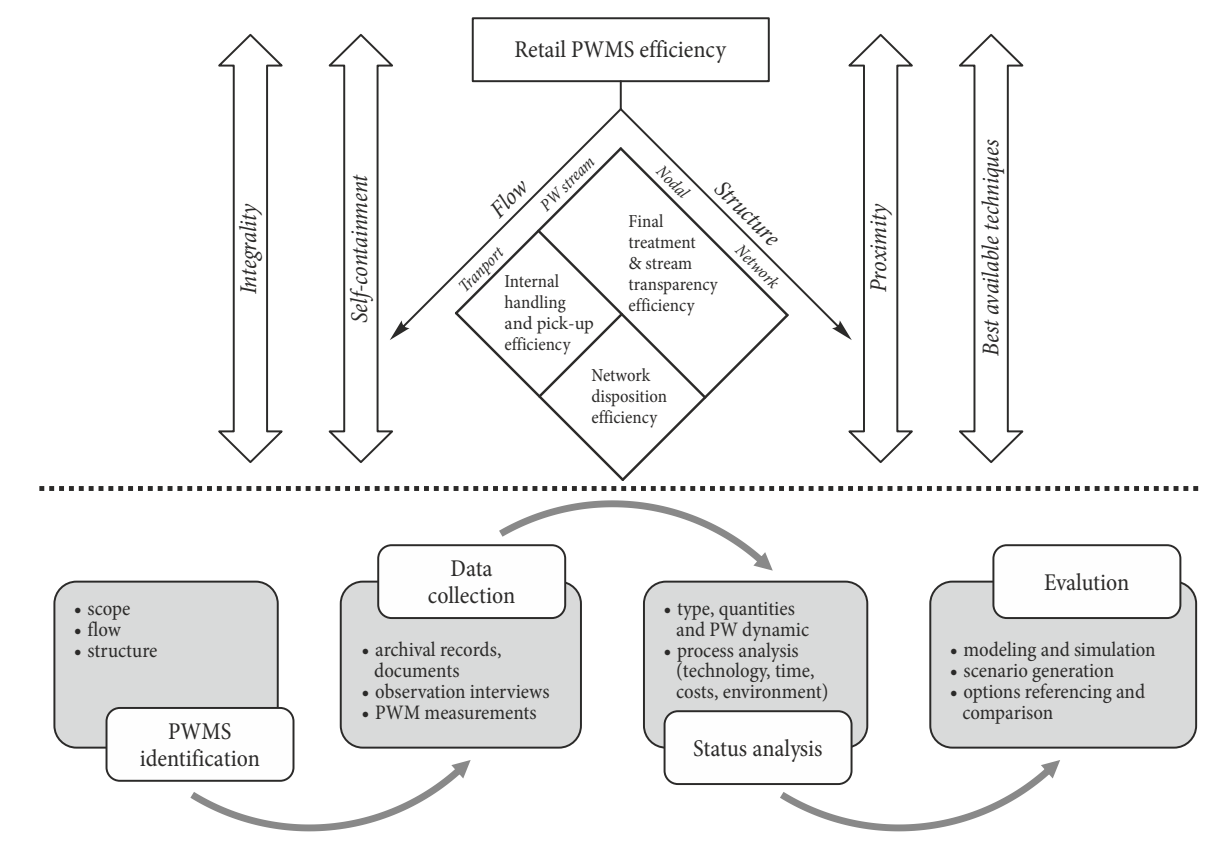

Figure 3. Employed analytical framework and methodology with PWMS efficiency model 


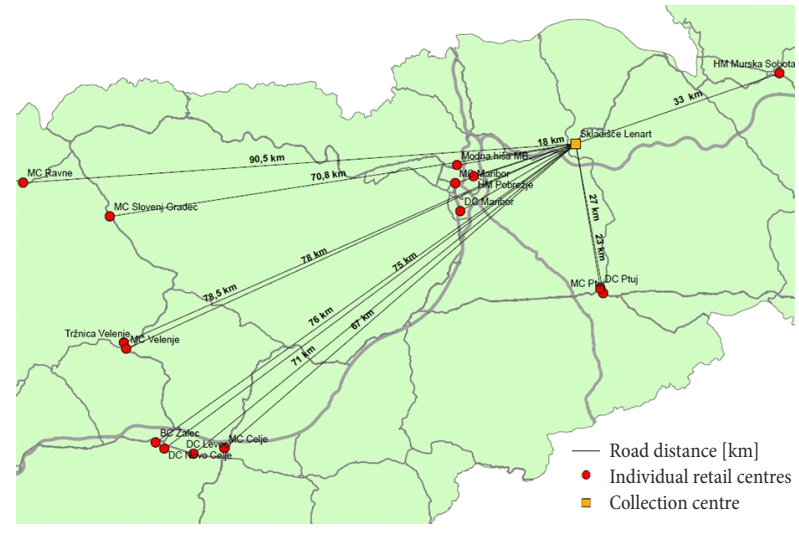

Figure 5. Current PW transportation system for PW removal

We also studied the possible rationalization of trips and, therefore, the possibility of reducing transportation costs. In the network analysis, the termination points represent collection centres of two PW companies and the source points the observed RCs of eastern Slovenian region.

Plastic and paper fractions are collected in 15 points of origin and then transported to the collection centre (Table 1).

When calculating the indicator, we incorporated net tonne-kilometre, which is expressed as the product of the mass of transported PW without the mass of transport means with the actual transport distance for each route (small RCs, HMs, DCs and other types of centres). The full distance of transportation of waste paper for the selected origin point in eastern Slovenia was in one year 88236.86 tonne-kilometres.

The variance of $\mathrm{km}$ is 729.44 and standard deviation of mileage is 27.01. Our goal is to rationalize the collection system of PW, which will be achieved by reducing the number of kilometres from source locations to the observed collection centre. With streamlining we will reduce transportation costs and reduce environmental impact due to minimization of driven kilometres and the resulting emissions. An individual point of origin will be assigned the nearest collection centre, which the observed retailer for various undisputed reasons has not chosen for its domain collection centre. In this process, we will, therefore, take into account the following collection centres in 7 locations from other different WM company.

Table 2 shows the optimum allocation of the retailer's source locations to the nearest collection centre. As it can be seen from the results, PW by this arrangement could be taken away to 6 collection centres instead of only one chosen collection centre which is also very distant from most RCs. In this arrangement, the total volume of transportation of waste paper in the selected centres in 20XX would decline from 88236.86 to 39775.46 tonne-kilometres, representing a 55\% decrease in mileage.

As we can see from Table 2 we have divided, the eastern Slovenian collection region in 6 new collecting
Table 1. The parameters of the existing RL network

\begin{tabular}{|c|c|c|c|}
\hline $\begin{array}{c}\text { Retail } \\
\text { centre }\end{array}$ & $\begin{array}{c}\text { Waste paper } \\
\text { amount in } \\
\text { 20XX [tonne] }\end{array}$ & $\begin{array}{c}\text { Distance to } \\
\text { collection } \\
\text { centre } \\
\text { [kilometres] }\end{array}$ & $\begin{array}{c}\text { Measuring unit of } \\
\text { transported goods } \\
\text { [tonne-kilometres] }\end{array}$ \\
\hline$a_{1}$ & 18.080 & 27 & 488.16 \\
\hline$c_{1}$ & 133.530 & 26.5 & 3538.545 \\
\hline$a_{2}$ & 45.110 & 90.5 & 4082.455 \\
\hline$a_{3}$ & 65.870 & 70.8 & 4663.596 \\
\hline$d_{1}$ & 5.180 & 18 & 93.24 \\
\hline$a_{4}$ & 143.680 & 18,6 & 2672.448 \\
\hline$c_{2}$ & 1494.130 & 23 & 34364.99 \\
\hline$c_{3}$ & 113.360 & 75 & 8502 \\
\hline$d_{2}$ & 56.730 & 76 & 4311.48 \\
\hline$c_{4}$ & 40.110 & 71 & 2847.81 \\
\hline$a_{5}$ & 143.250 & 67 & 9597.75 \\
\hline$a_{6}$ & 43.570 & 78.5 & 3420.245 \\
\hline$b_{1}$ & 63.100 & 33 & 2082.3 \\
\hline$b_{2}$ & 67.650 & 16 & 1082.4 \\
\hline$a_{7}$ & 83.198 & 78 & 6489.444 \\
\hline & Total & & 88236.86 \\
\hline
\end{tabular}

sub-systems (5 sub-systems from one collecting company and 1 from current collecting company where they already transport PW (Figure 6)). Variance of mileage is now 47.76 and standard deviation of mileage is 6.91 .

We used ArcGIS software, extension Network Analyst. Algorithm was Dijkstra's shortest path. Computation was less than one minute. Network scale was 15 points. Results are local optimum. We used road network restriction, one way streets, prohibition of motor vehicles and speed limit.

Table 3 presents performance indicators which are: cost of transportation activities (P01), distance [tonnekilometres] (P02), collection coverage (P03) and service frequency (P04). This performance indicators are usually very simple to calculate and should rely on a very accurate set of data.

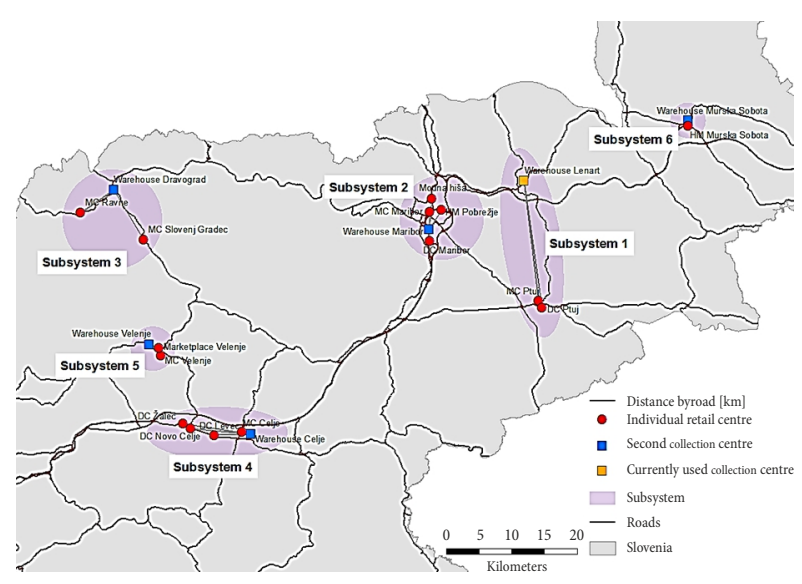

Figure 6. Display of an optimized collection system 
Table 2. Parameters of alternative RL network

\begin{tabular}{|c|c|c|c|c|}
\hline Retail centre & $\begin{array}{c}\text { Nearest collection } \\
\text { centre }\end{array}$ & $\begin{array}{c}\text { Distance to collection centre } \\
\text { [kilometres] }\end{array}$ & $\begin{array}{l}\text { Amount of waste paper } \\
\text { in 20XX [tonne] }\end{array}$ & $\begin{array}{l}\text { Measuring unit of transported } \\
\text { goods [tonne-kilometres] }\end{array}$ \\
\hline$a_{1}$ & \multirow{2}{*}{1} & 22.83 & 18.08 & 412.7664 \\
\hline$c_{1}$ & & 23.14 & 1494.13 & 34574.1682 \\
\hline$a_{2}$ & \multirow{4}{*}{2} & 2.27 & 133.53 & 303.1131 \\
\hline$a_{3}$ & & 4.72 & 5.18 & 24,4496 \\
\hline$d_{1}$ & & 2.51 & 143.68 & 360.6368 \\
\hline$a_{4}$ & & 4.96 & 67.65 & 335.544 \\
\hline$c_{2}$ & \multirow{2}{*}{3} & 7.91 & 45.11 & 356.8201 \\
\hline$c_{3}$ & & 9.94 & 65.87 & 654.7478 \\
\hline$d_{2}$ & \multirow{4}{*}{4} & 10.55 & 113.36 & 1195.948 \\
\hline$c_{4}$ & & 11.46 & 56.73 & 650.1258 \\
\hline$a_{5}$ & & 6.37 & 40.11 & 255.5007 \\
\hline$a_{6}$ & & 2.71 & 143.25 & 388.2075 \\
\hline$b_{1}$ & \multirow{2}{*}{5} & 0.96 & 43.57 & 41.8272 \\
\hline$b_{2}$ & & 1.67 & 83.20 & 138.94066 \\
\hline$a_{7}$ & 6 & 1.31 & 63.10 & 82.661 \\
\hline \multicolumn{4}{|c|}{ Total } & 39775.46 \\
\hline
\end{tabular}

Table 3. Performance indicators

\begin{tabular}{|l|c|c|}
\hline $\begin{array}{l}\text { Performance } \\
\text { indicators }\end{array}$ & 20XX & 20XX +1 \\
\hline $\begin{array}{l}\text { P01 Cost of transportation } \\
\text { activities }\end{array}$ & hidden data & hidden data \\
\hline $\begin{array}{l}\text { P02 Distance } \\
\text { [tonne-kilometres] }\end{array}$ & 88236.86 & 39775.46 \\
\hline P03 Collection coverage & one system & six subsystems \\
\hline P04 Service frequency & $\begin{array}{l}\sim \text { twice a } \\
\text { week/centre }\end{array}$ & $\begin{array}{l}\sim \text { one per two } \\
\text { weeks/centre }\end{array}$ \\
\hline
\end{tabular}

\section{Policy implications for decision makers}

In parallel, nodal and flow interface at the transport level includes internal handling efficiencies in connection to time and space utilization and pick-up/haulage efficiency which could live to improvements for decisions makers. Different collection technologies were tested by adding press-containers with and without self-loading mechanism, which could at the same time facilitate the most labour intensive activity: PW transfer from RLCs into containers, and reduce the number of yearly required pick-ups by a factor of up to 6, which approximately corresponds to the compaction ratio between bulk and pressed refuse (the benchmark values were obtained from several manufacturers and empirically from the hauled press-container weight data at the central and regional DCs, where the technology is being employed to prepare the PW prior secondary pick-up by the waste collector). At the same time, using the combination of waste stream and nodal perspective enabled the conceptualization of a source-based ROP PW handling cost model. We have conducted continuous 1-week measurements of collec- tion RLCs in the selected HM by weighing them before they were emptied into external collection containers. The weekly sample included 112 outbound PW collection RLCs, which were weighed and photographed and whose handling activities were timed (Figure 7). Measure or attribute, which determines the activity costs was PW quantity, expressed as the average estimate of net RLC weight: cost driver unit measurement was translated into the net weight of full PW-filled RLC (RLC equivalent unit, REU). With the transposition of unit measurement into weight dimension and generalization of sampled waste stream composition a cost allocation model can be specifically applied to any ROP, using the following inputs: facility layout, PW type-specific quantities and process technology (containers, compactors, or back loading). Further costs, associated with the extended internal primary collection and preliminary storage, when taking into account also the DOPs and smaller ROPs, were alternatively proposed to include several extra factors: RLC loading/unloading, delivery vehicle downtime, dedicated storage and handling area floor-space, register-keeping and administration and opportunity costs (costs of interference with the primary business activities and forward flow). Lastly, the final efficiency intersection of structural and waste stream components included the evaluation of transparency and shares of PW output according to different waste hierarchy treatment methods (EC 2008) and compared to the inbound goods flow. For 2 PW removals exact HM PW output, restricted to the retailer as the anchor tenant of the shopping centre, was empirically measured. In addition to HM generated paper/cardboard PW, a surplus of $60 \%$ and $100 \%$ of PW that had been processed by the HM's PWMS during the observation period indicated an existence of unaccounted waste streams, indicating secondary shopping centre tenants and other sources contributions or in-process imbalances. 


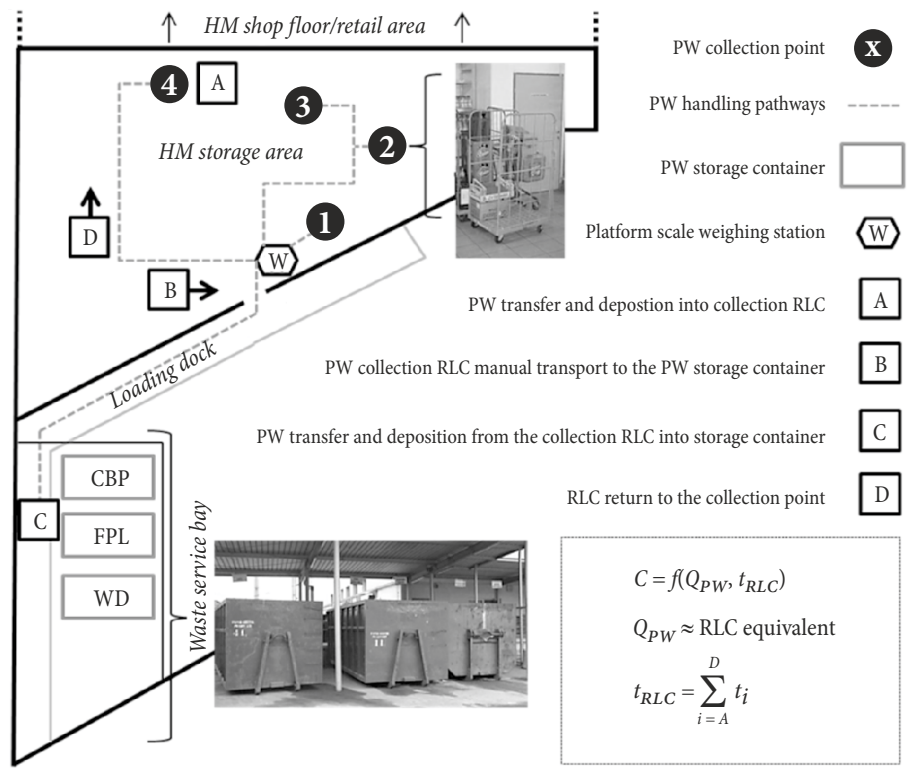

Figure 7. Selected HM's PW handling process layout with general cost model

Similarly, a regression analysis, using volumes of goods received and issued and the number of handled transport units as predictors from referential warehouses that do not handle PW back loading, indicated, that in the non-integrated part of the PWMS (one with intermediary storage at DCs) as high as $86 \%$ of the $\mathrm{PW}$, which is aggregately assigned to DCs, is coming from individual smaller ROP and is masked in the DOP PW output, while the unaccounted stream, resulting from pure DC operations makes up the rest.

Presented hierarchical efficiency model, extending the principles of Samuelsson and Tilanus' (1997) transport physical efficiency, was applied to a real-life retail PWMS evaluation problem, where we built upon logistics system analysis approaches, proposed by Coyle et al. (2016). Besides what to explore and how to analyse and juxtapose PWMS characteristics with ideal reference options, specific guidelines were also acknowledged on a flow and structural PWMS level: the network should enable PW recovery at the nearest available facility with best available techniques (EC 2008, 1996), without overburdening the business system's regular processes by taking on excessive and sustainability-wise unjustifiable PW amounts (self-containment) and recognizing RL processes in full length (integrity). The methodology allows for different evaluations: internal benchmarking of peer ROP, external company-wide benchmarking or ideal options comparisons with incumbent PWMS characteristics. It enables a conceptually proven approach and provides a structured extension to quantitatively based methods that can be used in RL and WMS problems, such as MCDM and DEA analysis, as well as OR and optimization procedures. The proposed and demonstrated framework was applied to a limited retail network scope, although it provides a basis for decision-making and potentially regular or one-off evaluations on a different company and network levels. Further research gaps that may be considered in the future are the inclusion of
DOP operations in the scope of PWMS evaluation, management of unaccounted waste streams, and to achieve a system-wide transparency, coupled with complete source output visibility, a feasibility study for setting up a smaller store format PW quantity monitoring and registry.

\section{Conclusions}

PW is a significant retail challenge. If its associated RL is to become a true function of sustainable development that could also be sustained in the long-term not only on a declarative level, but also on the level of underlying processes, conventional efficiency thinking must be adapted to a sustainability context: 'making or selling more with less', coupled with 'doing or processing more with causing less', while retaining economic viability. Better reverse processes visibility and well-defined pertaining performance measures should contribute towards an organizational and physical network structures re-evaluation, founded on tangible and practicallyrelevant criteria, as it is presented - in improved physical organization, better system transparency and potential cost reductions.

PW RL is a specific but integral part of retail operations that has not gained much attention on efficiencyside and operational performance. Thoroughly designed $\mathrm{RL}$, however, has to consider and balance the relationships between primary business operations and WM activities; especially in retail, where companies have limited options for closed-loop micro-recycling and are faced with extensive PW quantities, which are an intrinsic by-product of merchandise market placement. Consequently, an integrated approach, combining flow, network, origination points and conveyance aspects of PW logistics was designed to comprehensively assess the current RL system under the following guiding principles: self-containment, integrity, legislative compliance, proximity and best available techniques. 
As we found out, in our case the solution for reduction is in dividing the whole retailer's eastern area with one collection centre to 6 subareas with 6 collection centres for PW. With this solution, we reduce a number of tonne-kilometres from 88236.86 to only 39775.46 , which represents (55\% reduction in tonne-kilometres). The contribution is the development of an integrated analysis and improvement level, for transport as well as in store logistics.

\section{References}

Abeliotis, K.; Karaiskou, K.; Togia, A.; Lasaridi, K. 2009. Decision support systems in solid waste management: a case study at the national and local level in Greece, Global NEST Journal 11(2): 117-126.

Bain, A.; Ashton, W.; Shenoy, M. 2009. Resource reuse and recycling in an Indian industrial network: efficiency and flexibility considerations, in 2009 Second International Conference on Infrastructure Systems and Services: Developing 21st Century Infrastructure Networks (INFRA), 9-11 December 2009, Chennai, India, 1-7.

https://doi.org/10.1109/INFRA.2009.5397868

Cooper, W. W.; Seiford, L. M.; Zhu, J. 2011. Data envelopment analysis: history, models, and interpretations, International Series in Operations Research \& Management Science 164: 1-39. https://doi.org/10.1007/978-1-4419-6151-8_1

Coyle, J. J.; Langley, C. J.; Gibson, B. J.; Novack, R. A. 2016. Supply Chain Management: a Logistics Perspective. 10th edition, South-Western College Pub. 639 p.

Da Cruz, N. F.; Ferreira, S.; Cabral, M.; Simões, P.; Marques, R. C. 2014. Packaging waste recycling in Europe: is the industry paying for it?, Waste Management 34(2): 298308. https://doi.org/10.1016/j.wasman.2013.10.035

EC. 2008. Directive 2008/98/EC of the European Parliament and of the Council of 19 November 2008 on Waste and Repealing Certain Directives (Text with EEA Relevance). 28 p. Available from Internet: http://eur-lex.europa.eu/legal-content/ $\mathrm{EN} / \mathrm{TXT} /$ ?qid=1493496756513\&uri=CELEX:32008L0098

EC. 1996. Council Directive 96/61/EC of 24 September 1996 concerning Integrated Pollution Prevention and Control (IPPC). 15 p. Available from Internet: http://eur-lex.europa. eu/legal-content/EN/TXT/?uri=CELEX:31996L0061

EC. 1994. European Parliament and Council Directive 94/62/EC of 20 December 1994 on Packaging and Packaging Waste. 14 p. Available from Internet: http://eur-lex.europa.eu/legalcontent/en/ALL/?uri=CELEX:31994L0062

EC DGE. 2012. Preparing a Waste Management Plan: a Methodological Guidance Note. European Commission Directorate-General Environment (EC DGE). 117 p. Available from Internet: http://ec.europa.eu/environment/waste/ plans/pdf/2012_guidance_note.pdf

EEA. 2005. Effectiveness of Packaging Waste Management Systems in Selected Countries: an EEA Pilot Study. EEA Report No 3/2005. European Environment Agency (EEA). 96 p. Available from Internet: http://www.eea.europa.eu/publications/eea_report_2005_3

EEC. 1975. Council Directive 75/442/EEC of 15 July 1975 on Waste. 10 p. Available from Internet: http://eur-lex.europa. eu/LexUriServ/LexUriServ.do?uri=CONSLEG:1975L0442: 20031120:EN:PDF

DfT. 2004. Efficiency of Reverse Logistics. Reference FL 0217. Department for Transport (DfT), UK.

Fernie, J.; Sparks, L.; McKinnon, A. C. 2010. Retail logistics in the UK: past, present and future, International Journal of Retail \& Distribution Management 38(11/12): 894-914. https://doi.org/10.1108/09590551011085975
Guimarães, B.; Simões, P.; Marques, R. C. 2010. Does performance evaluation help public managers? A balanced scorecard approach in urban waste services, Journal of Environmental Management 91(12): 2632-2638.

https://doi.org/10.1016/j.jenvman.2010.07.039

Hogland, W.; Stenis, J. 2000. Assessment and system analysis of industrial waste management, Waste Management 20(7): 537-543. https://doi.org/10.1016/S0956-053X(00)00020-9

Huge-Brodin, M. 1997. Reverse Logistics Systems: an Interorganisational Perspective, Focusing on Paper Recycling. Linköping Studies in Science and Technology. Thesis No 630, Department of Management and Economics, Logistics, Linköping University, Sweden. $156 \mathrm{p}$.

Maynard, S.; Cherrett, T. 2009. Characteristics of Retail Waste Logistics on Winchester High Street: Initial findings from the High Street Business Managers Survey. University of Southampton, UK.

McGhie, C. 2001. Packaging and Reverse Logistics. Report 20002001. Scottish Institute of Sustainable Technology, UK.

McLeod, F; Hickford, A.; Maynard, S.; Cherrett, T.; Allen, J. 2008. Developing Innovative and More Sustainable Approaches to Reverse Logistics for the Collection, Recycling and Disposal of Waste Products from Urban Centres: Literature Review and Identification of Opportunities. University of Southampton \& University of Westminster, UK. 145 p.

Pitt, M. 2005. Trends in shopping centre waste management, Facilities 23(11/12): 522-533.

https://doi.org/10.1108/02632770510618480

Pitt, M.; Smith, A. 2003. An assessment of waste management efficiency at BAA airports, Construction Management and Economics 21(4): 421-431. https://doi.org/10.1080/0144619032000089599

Samuelsson, A.; Tilanus, B. 1997. A framework efficiency model for goods transportation, with an application to regional less-than-truckload distribution, Transport Logistics 1(2): 139-151. https://doi.org/10.1163/156857097300151660

Shakantu, W.; Muya, M.; Tookey, J.; Bowen, P. 2008. Flow modelling of construction site materials and waste logistics: a case study from Cape Town, South Africa, Engineering, Construction and Architectural Management 15(5): 423439. https://doi.org/10.1108/09699980810902721

Šimenc, M., Lisec, A. 2012. A multidimensional approach to packaging waste reverse logistics evaluation in retailing, in Proceedings of papers of the 17th International Symposium on Logistics (ISL 2012): New Horizons in Logistics and Supply Chain Management, 8-11 July 2012, Cape Town, South Africa, 501-508.

Triantafyllou, M. K.; Cherrett, T. 2010. Waste Management and 'Take-Back' Processes in a Dedicated Shopping Centre: Results from the WestQuay Shopping Centre Managers Survey, Transportation Research Group, School of Civil Engineering and the Environment, University of Southampton, UK. 61 p. https://doi.org/10.13140/2.1.2042.1440

UNEP. 2009. Developing Integrated Solid Waste Management Plan: Training Manual. Volume 2: Assessment of Current Waste Management System and Gaps Therein. United Nations Environment Programme (UNEP). 25 p. Available from Internet: http://www.unep.or.jp/ietc/Publications/spc/ ISWMPlan_Vol2.pdf

WBCSD. 2000. Eco-Efficiency: Creating More Value with Less Impact. World Business Council for Sustainable Development (WBCSD), Geneva. 36 p.

Yin, R. K. 2013. Case Study Research: Design and Methods. 5th edition, SAGE Publications Inc. $312 \mathrm{p}$.

Yoshinaga, Y.; Nishina, Y.; Inoko, M.; Saito, S.; Tsuyuguchi, T. 2002. Inverse logistics and recycling facilities network evaluation system, NKK Technical Review 87: 45-49. 